\title{
TECHNICAL INSIGHTS FOR SALTSTONE PA MAINTENANCE
}

\section{Cementitious Barriers Partnership}

\author{
May 2011
}

CBP-RP-2010-013-01, Rev. 0 



\title{
TECHNICAL INSIGHTS FOR SALTSTONE PA MAINTENANCE
}

\author{
Sohini Sarkar, S. Mahadevan and David Kosson \\ Vanderbilt University, School of Engineering \\ Consortium for Risk Evaluation with Stakeholder Participation III \\ Nashville, TN 37235 \\ Eric Samson \\ SIMCO Technologies Inc. \\ Quebec, Canada \\ Hans Meeussen and Hans van der Sloot \\ Energy Research Centre of the Netherlands (ECN) \\ Petten, Netherlands \\ Hans van der Sloot \\ Hans van der Sloot Consultancy \\ Langedijk, The Netherlands \\ Greg Flach \\ Savannah River National Laboratory \\ Aiken, SC 29808
}




\section{ACKNOWLEDGEMENTS}

This report was prepared for the United States Department of Energy in part under Contract No. DE-AC0908SR22470 and is an account of work performed in part under that contract. Reference herein to any specific commercial product, process, or service by trademark, name, manufacturer, or otherwise does not necessarily constitute or imply endorsement, recommendation, or favoring of same by Savannah River Nuclear Solutions or by the United States Government or any agency thereof. The views and opinions of the authors expressed herein do not necessarily state or reflect those of the United States Government or any agency thereof.

and

This report is based on work supported by the U. S. Department of Energy, under Cooperative Agreement Number DE-FC01-06EW07053 entitled 'The Consortium for Risk Evaluation with Stakeholder Participation III' awarded to Vanderbilt University. The opinions, findings, conclusions, or recommendations expressed herein are those of the author(s) and do not necessarily represent the views of the U.S. Department of Energy or Vanderbilt University.

\section{DISCLAIMER}

This work was prepared under an agreement with and funded by the U. S. Government. Neither the U.S. Government or its employees, nor any of its contractors, subcontractors or their employees, makes any express or implied: 1. warranty or assumes any legal liability for the accuracy, completeness, or for the use or results of such use of any information, product, or process disclosed; or 2. representation that such use or results of such use would not infringe privately owned rights; or 3. endorsement or recommendation of any specifically identified commercial product, process, or service. Any views and opinions of authors expressed in this work do not necessarily state or reflect those of the United States Government, or its contractors, or subcontractors.

\section{Printed in the United States of America}

United States Department of Energy Office of Environmental Management Washington, DC

\section{This document is available on the U.S. DOE Information Bridge and on the CBP website: http://cementbarriers.org/ An electronic copy of this document is also available through links on the following website: http://srnl.doe.gov/}




\title{
FOREWORD
}

The Cementitious Barriers Partnership (CBP) Project is a multi-disciplinary, multi-institutional collaboration supported by the United States Department of Energy (US DOE) Office of Waste Processing. The objective of the CBP project is to develop a set of tools to improve understanding and prediction of the long-term structural, hydraulic, and chemical performance of cementitious barriers used in nuclear applications.

A multi-disciplinary partnership of federal, academic, private sector, and international expertise has been formed to accomplish the project objective. In addition to the US DOE, the CBP partners are the Savannah River National Laboratory (SRNL), Vanderbilt University (VU) / Consortium for Risk Evaluation with Stakeholder Participation (CRESP), Energy Research Center of the Netherlands (ECN), and SIMCO Technologies, Inc. The Nuclear Regulatory Commission (NRC) is providing support under a Memorandum of Understanding. The National Institute of Standards and Technology (NIST) is providing research under an Interagency Agreement. Neither the NRC nor NIST are signatories to the Cooperative Research and Development Agreement (CRADA).

The periods of cementitious performance being evaluated are up to or longer than 100 years for operating facilities and longer than 1000 years for waste management. The set of simulation tools and data developed under this project will be used to evaluate and predict the behavior of cementitious barriers used in nearsurface engineered waste disposal systems, e.g., waste forms, containment structures, entombments, and environmental remediation, including decontamination and decommissioning analysis of structural concrete components of nuclear facilities (spent-fuel pools, dry spent-fuel storage units, and recycling facilities such as fuel fabrication, separations processes). Simulation parameters will be obtained from prior literature and will be experimentally measured under this project, as necessary, to demonstrate application of the simulation tools for three prototype applications (waste form in concrete vault, high-level waste tank grouting, and spent-fuel pool). Test methods and data needs to support use of the simulation tools for future applications will be defined.

The CBP project is a five-year effort focused on reducing the uncertainties of current methodologies for assessing cementitious barrier performance and increasing the consistency and transparency of the assessment process. The results of this project will enable improved risk-informed, performance-based decision-making and support several of the strategic initiatives in the DOE Office of Environmental Management Engineering \& Technology Roadmap. Those strategic initiatives include 1) enhanced tank closure processes; 2) enhanced stabilization technologies; 3) advanced predictive capabilities; 4) enhanced remediation methods; 5) adapted technologies for site-specific and complex-wide D\&D applications; 6) improved SNF storage, stabilization and disposal preparation; 7) enhanced storage, monitoring and stabilization systems; and 8) enhanced long-term performance evaluation and monitoring.

\author{
Christine A. Langton, PhD \\ Savannah River National Laboratory \\ David S. Kosson, PhD \\ Vanderbilt University / CRESP
}




\section{CONTENTS}

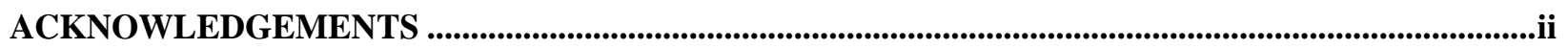

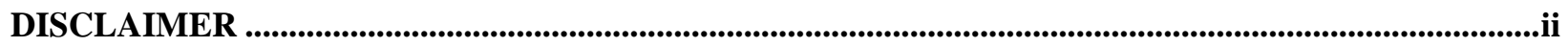

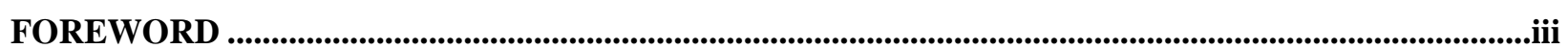

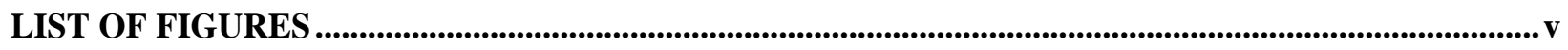

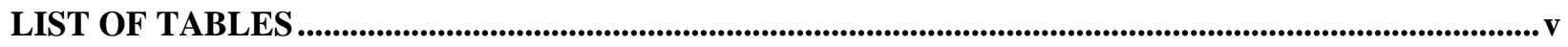

LIST OF ACRONYMS AND ABBREVIATIONS …................................................................................

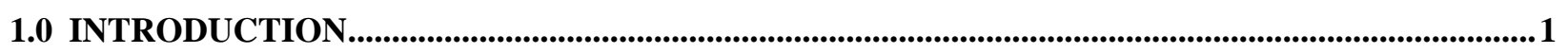

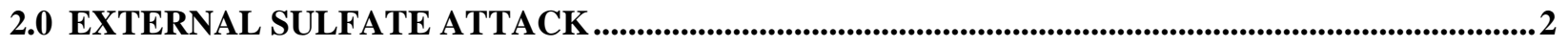

2.1 Multi-Layer STADIUM® Simulations .......................................................................................

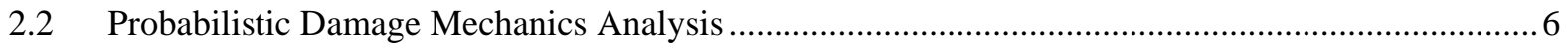

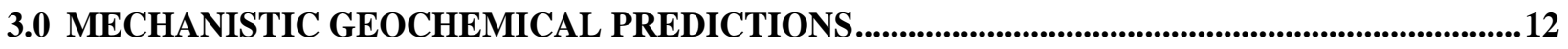

$3.1 \quad$ Saltstone Reduction Capacity ……………….............................................................................. 12

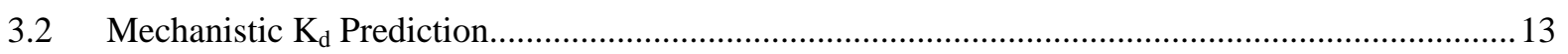

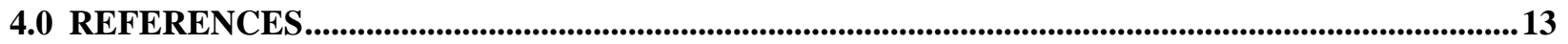




\section{LIST OF FIGURES}

Figure 1. Schematic representation of demonstration cases; reproduced from Samson (2010)....................... 4

Figure 2. Sulfate concentration at the concrete-waste interface; reproduced from Samson (2010)................. 5

Figure 3. External sulfate attack modeling approach presented by Sarkar et al. (2010); reproduced

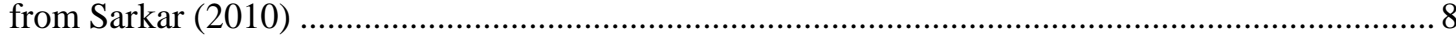

Figure 4. Stress-strain and damage relationships for concrete under tension; reproduced from Sarkar

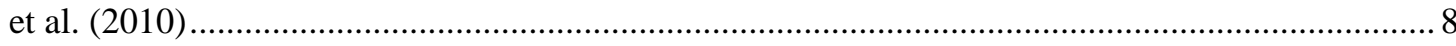

Figure 5. Measured and simulated total calcium content after one year of exposure; reproduced from

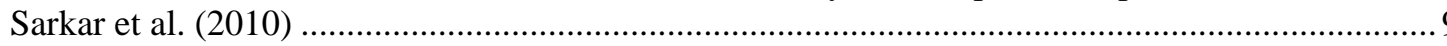

Figure 6. Measured and simulated total sulfur content after one year of exposure; reproduced from

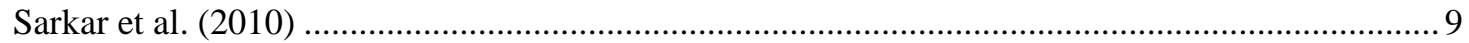

Figure 7. Extended framework for modeling external sulfate attack; reproduced from Sarkar (2010) .......... 10

Figure 8. Probabilistic durability assessment using single loop Monte Carlo simulation; reproduced

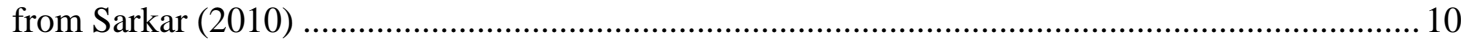

Figure 9. Sulfate exposure scenario; reproduced from Sarkar (2010)............................................................ 11

Figure 10. Cumulative probability for complete damage; reproduced from Sarkar (2010)............................ 11

\section{LIST OF TABLES}

Table 1. Demonstration case summary; reproduced from Samson (2010) ….................................................5

Table 2. Mix proportions from SIMCO (2009b) and Savannah River saltstone ........................................... 6

Table 3. Sensitivity study of concrete durability (years) …......................................................................... 12 


\section{LIST OF ACRONYMS AND ABBREVIATIONS}

CBP Cementitious Barriers Partnership

CRESP Consortium for Risk Evaluation with Stakeholder Participation

DLL Dynamic-link Library

DOE Department of Energy

ECN Energy Research Centre of the Netherlands

GTG GoldSim Technology Group

NIST National Institute of Standards and Technology

NRC Nuclear Regulatory Commission

SRNL Savannah River National Laboratory

STADIUM ${ }^{\circledR} \quad$ Software for Transport and Degradation in Unsaturated Materials

XML eXtensible Markup Language 


\title{
TECHNICAL INSIGHTS FOR SALTSTONE PA MAINTENANCE
}

\author{
Sohini Sarkar, S. Mahadevan, and David Kosson \\ Vanderbilt University, School of Engineering \\ Consortium for Risk Evaluation with Stakeholder Participation III \\ Nashville, TN 37235 \\ Eric Samson \\ SIMCO Technologies Inc. \\ Quebec, Canada \\ Hans Meeussen and Hans van der Sloot \\ Energy Research Centre of the Netherlands (ECN) \\ Petten, Netherlands \\ Hans van der Sloot \\ Hans van der Sloot Consultancy \\ Langedijk, The Netherlands \\ Greg Flach \\ Savannah River National Laboratory \\ Aiken, SC 29808
}

\subsection{INTRODUCTION}

The Cementitious Barriers Partnership (CBP) is a collaborative program sponsored by the US DOE Office of Waste Processing. The objective of the CBP is to develop a set of computational tools to improve understanding and prediction of the long-term structural, hydraulic, and chemical performance of cementitious barriers and waste forms used in nuclear applications. CBP tools are expected to better characterize and reduce the uncertainties of current methodologies for assessing cementitious barrier performance and increase the consistency and transparency of the assessment process, as the five-year program progresses.

In September 2009, entering its second year of funded effort, the CBP sought opportunities to provide nearterm tangible support to DOE Performance Assessments (PAs). The Savannah River Saltstone Disposal Facility (SDF) was selected for the initial PA support effort because 1) cementitious waste forms and barriers play a prominent role in the performance of the facility, 2) certain important long-term behaviors of cementitious materials composing the facility are uncertain, 3) review of the SDF PA by external stakeholders is ongoing, and 4) the DOE contractor responsible for the SDF PA is open to receiving technical assistance from the CBP.

A review of the current (SRR Closure \& Waste Disposal Authority 2009) and prior Saltstone PAs (e.g., Cook et al. 2005) suggested five potential opportunities for improving predictions. The candidate topics considered were 1) concrete degradation from external sulfate attack, 2) impact of atmospheric exposure to concrete and 
grout before closure, such as accelerated slag and Tc-99 oxidation, 3) mechanistic prediction of geochemical conditions, 4) concrete degradation from rebar corrosion due to carbonation, and 5) early age cracking from drying and/or thermal shrinkage.

The candidate topics were down-selected considering the feasibility of addressing each issue within approximately six months, and compatibility with existing CBP expertise and already-planned activities. Based on these criteria, the five original topics were down-selected to two: external sulfate attack and mechanistic geochemical prediction. For each of the selected topics, the CBP communicated with the PA analysts and subject matter experts at Savannah River to acquire input data specific to the Saltstone facility and related laboratory experiments. Simulations and analyses were performed for both topics using STADIUM® (SIMCO 2008), LeachXSTM/ORCHESTRA (ECN 2007, Meeussen 2003), and other software tools.

These supplemental CBP analyses produced valuable technical insights that can be used to strengthen the Saltstone PA using the ongoing PA maintenance process. This report in part summarizes key information gleaned from more comprehensive documents prepared by Sarkar et al. (2010), Samson (2010), and Sarkar (2010).

\subsection{EXTERNAL SULFATE ATTACK}

External sulfate attack has been identified as a primary mechanism for degradation of many cementitious materials used in nuclear applications including Saltstone concrete barriers (SRR Closure \& Waste Disposal Authority 2009). Predictions of external sulfate attack in the SDF PA are based on one-layer STADIUM ${ }^{\circledR}$ simulations of reactive transport using surrogate concrete formulations (SIMCO 2008). The STADIUM ${ }^{\circledR}$ model does not yet incorporate cracking or damage prediction. In the PA analysis, the formation of ettringite (an expansive mineral phase) is assumed to produce and coincide with physical damage in the form of cracking and/or spalling, with respect to computing hydraulic conductivity and diffusion coefficient averaged over the barrier thickness. However, transport properties (diffusion coefficient) in STADIUM® simulations are not altered to reflect the presence of cracking/spalling. The sulfate concentration at the interface between Saltstone grout and concrete barriers is estimated using approximate analytic solutions and imposed as the sulfate exposure level in analytic abstractions of the one-layer (concrete) STADIUM ${ }^{\circledR}$ simulations. The presence of several approximations in the overall PA sulfate attack analysis offers the opportunity for refined analyses by the CBP as described below.

\subsection{Multi-Layer STADIUM ${ }^{\circledR}$ Simulations}

Since the most recent PA analysis, experimental data have been acquired for the specific Savannah River Vault 1/4 and 2 concrete formulations (SIMCO 2009a) and a salt waste form (SIMCO 2009b) similar to Saltstone. These data can be used to define model simulations, instead of the approximate surrogate values used previously. Furthermore, STADIUM ${ }^{\circledR}$ is capable of simulating Saltstone grout in direct contact with a barrier concrete, thus eliminating the need to estimate interface concentration and impose approximate boundary conditions, as in the one-layer PA model. As a demonstration of STADIUM ${ }^{\circledR}$ capabilities under the CBP, Samson (2010) performed multi-layer simulations using updated material properties and initial conditions associated with Vault 2. These simulations suggest lower (more favorable) sulfate exposure levels than considered in the PA. 
The series of multi-layer STADIUM® demonstration cases performed by Samson (2010) are summarized by Figure 1 and Table 1. Key findings from this CBP study relative to the SDF PA are:

1. Material layers: A three-layer soil-concrete-waste model is not necessary for accurate prediction of ettringite front depth. Similar simulation results were observed for 3 meters, 1 meter, and no soil layers (Samson 2010, Figure 13). A two-layer concrete-waste model is adequate for predicting external sulfate attack with STADIUM ${ }^{\circledR}$.

Additional simulations were performed using waste thicknesses of 50, 100, 200, 300 and $500 \mathrm{~cm}$. STADIUM ${ }^{\circledR}$ results indicate that a waste thickness of at least three meters $(300 \mathrm{~cm})$ is needed in a two-layer model for long-term (10,000+ years) durability simulations (Samson 2010, Figure 6).

2. Computational mesh resolution: The baseline simulations were performed using 50 elements in the concrete layer and 120 in the salt waste layer. Two additional simulations were performed with $\pm 20 \%$ cell numbers. Ettringite profiles after 10,000 years are practically identical for all three mesh schemes (Samson 2010, Figure 16), indicating numerical dispersion is negligible at the nominal mesh resolution. The SDF PA analysis incorporated 90 elements in the concrete layer, which implies more than adequate computational mesh resolution.

3. Sulfate concentration at interface: The initial mineral assemblage and pore solution in the salt waste form are based on laboratory/room temperature conditions, about $23^{\circ} \mathrm{C}$ according to Dr. Eric Samson. The sulfate concentration in the simulated pore solution at this temperature is $131 \mathrm{mmol} / \mathrm{L}$ (Samson 2010, Table 6). The long-term field exposure condition is roughly $15^{\circ} \mathrm{C}$, the assumption for STADIUM ${ }^{\circledR}$ exposure simulations. Lowering the temperature from $23^{\circ} \mathrm{C}$ to $15^{\circ} \mathrm{C}$ to begin long-term durability simulations produced a lower sulfate concentration in the salt waste form, approximately 77 $\mathrm{mmol} / \mathrm{L}$ (Samson 2010, Figure 5) or 40\% lower than laboratory conditions. These observations indicate that the sulfate exposure levels assumed in the SDF PA, which are based on data from laboratory (room temperature) conditions, may be biased high relative to long-term field conditions.

Furthermore, STADIUM ${ }^{\circledR}$ simulations indicate that the sulfate concentration at the concrete-waste interface declines significantly over time (Samson 2010, Figure 6) as shown in Figure 2 (for varying waste thicknesses). The SDF PA analysis incorporates an interface concentration that is fixed through time at the initial value. The CBP simulations indicate that the SDF PA sulfate exposure levels are overestimated in out years, and over predict ettringite front movement (all else being equal).

4. Initial mineral assemblage: An alternative initial mineral assemblage was considered as a sensitivity exercise to specifically illustrate the possibility that ettringite does not form in concrete despite sulfate exposure from the adjoining salt waste form. Samson (2010, page 30) concludes:

"However, the most important result concerns the influence of different mineral assemblages in the Saltstone mixture. The second set of minerals used for the simulations did not initiate the penetration of an ettringite front in the concrete barrier despite the high sulfate concentration in the pore solution. The absence of ettringite means that the concrete is not subject to sulfate attack and could prove highly durable for an extensive period of time. This surprising result emphasizes the need for 
experimental research work in order to have a better understanding of the complex interaction between the salt waste material and the concrete barrier."

This insight could potentially be used to develop alternative Saltstone and/or concrete formulations that are more resistant to external sulfate attack by design.

SIMCO (2009b) describes laboratory characterization of a salt waste form that is referred to as "Saltstone" in the report. However, the mix proportions do not correspond exactly to the Savannah River specifications for that named material, as indicated in Table 2. Thus the tested material should be regarded as a surrogate for Savannah River Saltstone. Replacing the surrogate salt waste form with true saltstone would have some impact on the STADIUM® simulation results described above.

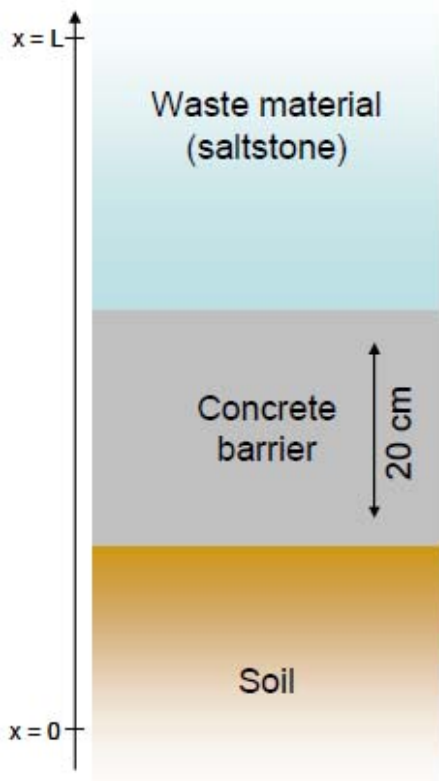

a) Multilayered case

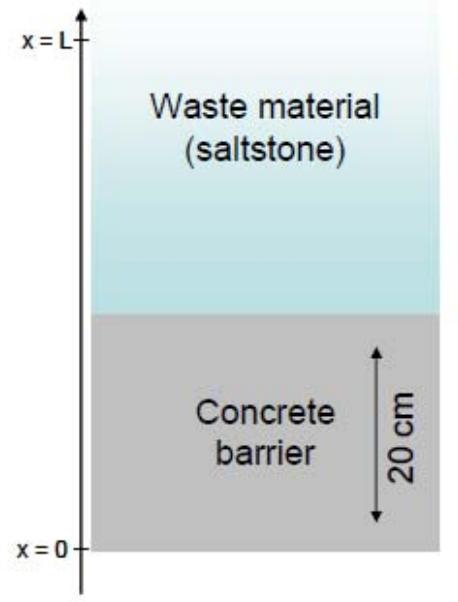

b) Simplified two-layer case

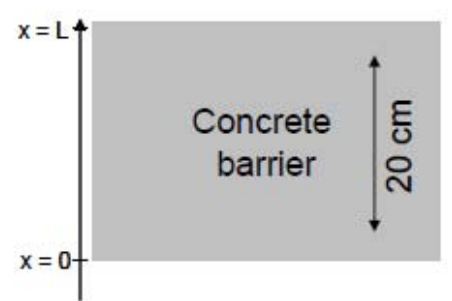

c) Single layer case

Figure 1. Schematic representation of demonstration cases; reproduced from Samson (2010). 
Table 1. Demonstration case summary; reproduced from Samson (2010).

\begin{tabular}{|c|c|c|c|c|}
\hline Series & Simulation name & Concrete & $\begin{array}{r}\text { Saltstone } \\
\text { Thickness }(\mathrm{cm})\end{array}$ & $\begin{array}{r}\text { Soil } \\
\text { Thickness } \\
(\mathrm{cm}) \\
\end{array}$ \\
\hline \multirow{5}{*}{$\begin{array}{l}\text { Effect of the Saltstone } \\
\text { thickness }\end{array}$} & Vault2-Saltstone-01 & Vault 2 & 50 & $\mathrm{~N} / \mathrm{A}$ \\
\hline & Vault2-Saltstone-02 & Vault 2 & 100 & $\mathrm{~N} / \mathrm{A}$ \\
\hline & Vault2-Saltstone-04 & Vault 2 & 200 & $\mathrm{~N} / \mathrm{A}$ \\
\hline & Vault2-Saltstone-05 & Vault 2 & 300 & N/A \\
\hline & Vault2-Saltstone-08 & Vault 2 & 500 & N/A \\
\hline \multirow{2}{*}{ Effect of soil thickness } & $\begin{array}{l}\text { Vault2-Saltstone-Soil- } \\
01\end{array}$ & Vault 2 & 300 & 100 \\
\hline & $\begin{array}{l}\text { Vault2-Saltstone-Soil- } \\
02\end{array}$ & Vault 2 & 300 & 300 \\
\hline \multirow{2}{*}{ Effect of mesh density } & Vault2-Saltstone-06 & Vault 2 & 300 & $\mathrm{~N} / \mathrm{A}$ \\
\hline & Vault2-Saltstone-07 & Vault 2 & 300 & N/A \\
\hline $\begin{array}{l}\text { Effect of concrete } \\
\text { properties }\end{array}$ & Vault14-Saltstone-01 & Vault $1 / 4$ & 300 & $\mathrm{~N} / \mathrm{A}$ \\
\hline $\begin{array}{l}\text { Effect of Saltstone } \\
\text { initial mineral } \\
\text { assemblage }\end{array}$ & Vault2-Saltstone-09 & Vault 2 & 300 & $\mathrm{~N} / \mathrm{A}$ \\
\hline
\end{tabular}

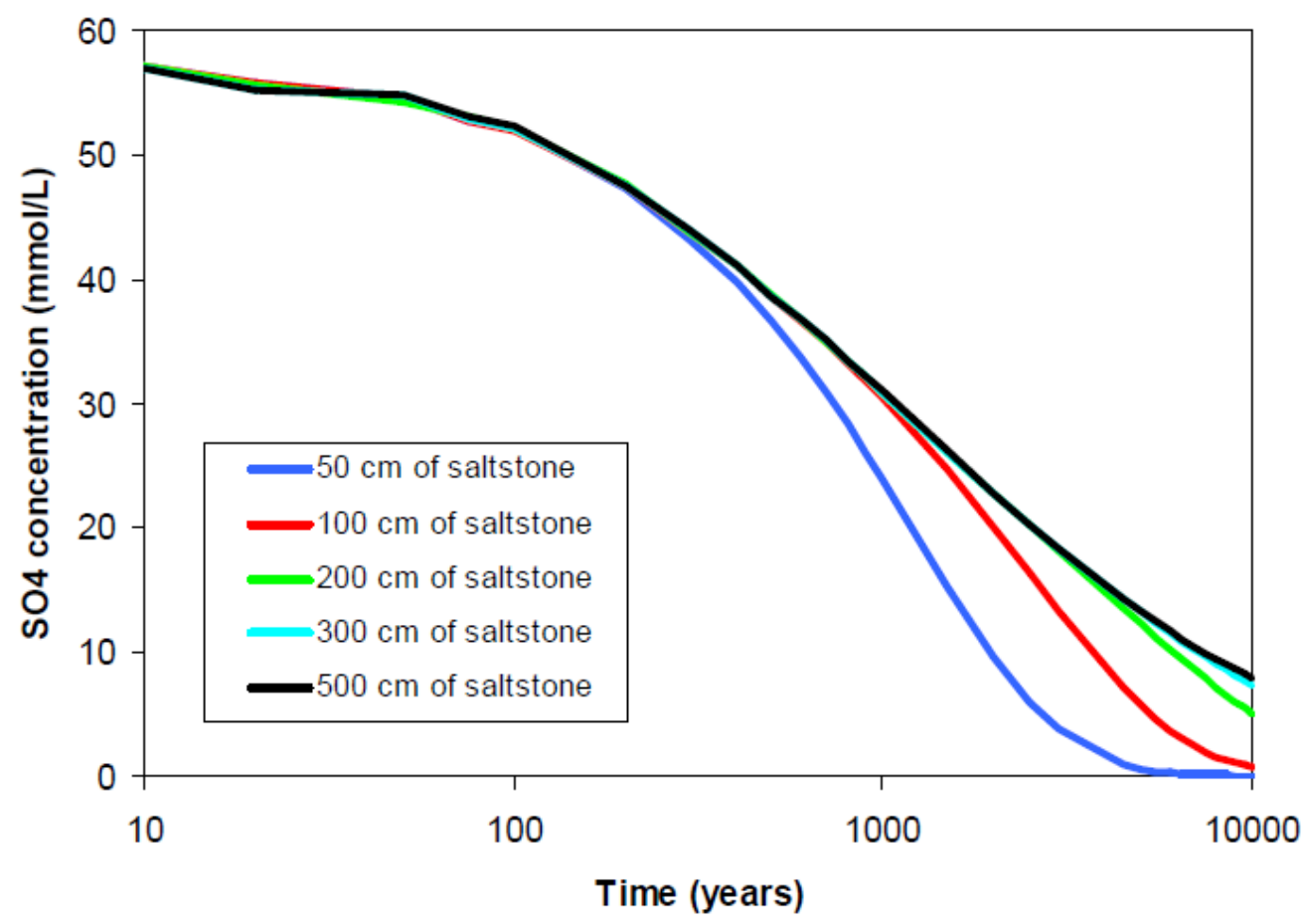

Figure 2. Sulfate concentration at the concrete-waste interface; reproduced from Samson (2010). 
Table 2. Mix proportions from SIMCO (2009b) and Savannah River saltstone.

\begin{tabular}{|c|c|c|}
\hline Ingredient & $\begin{array}{c}\text { SIMCO (2009b) } \\
\text { Salt Waste Form } \\
\text { Proportion }\end{array}$ & $\begin{array}{c}\text { Savannah River } \\
\text { Saltstone } \\
\text { Proportion }\end{array}$ \\
\hline Cement & $15 \%$ & $10 \%$ \\
\hline Blast Furnace Slag & $21 \%$ & $45 \%$ \\
\hline Fly Ash (Class F) & $65 \%$ & $45 \%$ \\
\hline
\end{tabular}

\subsection{Probabilistic Damage Mechanics Analysis}

External sulfate attack involves three coupled phenomena: a) transport of dissolved species through pore solution, b) chemical reactions between the pore solution and solid minerals, and c) physical damage to the solid matrix, such as cracking and/or spalling, resulting from formation of expansive mineral phases. Coupling of chemical reactions and transport ("reactive transport") has now been widely implemented in software. STADIUM ${ }^{\circledR}$ is a particular example that incorporates an extended Nerst-Planck equation for unsaturated media and accounts for electrical coupling between ionic species, chemical activity, transport due to water content gradient, and temperature effects. However, coupling damage mechanics to reactive transport in the context of external sulfate attack has proven more difficult (Glasser et al. 2008), although a number of empirical, mechanistic and numerical models have been presented in the literature (Atkinson and Hearne 1990, Tixier and Mobasher 2003, Maltais et al. 2004, Basista and Weglewski 2008).

Sarkar et al. (2010) have developed a new numerical model of coupled reactive transport and damage mechanics for simulating external sulfate attack (Figure 3) that builds upon these earlier efforts. The model explicitly tracks stress and strain through space and time, and predicts whether and how much damage would occur using stress-strain characteristics of that particular material (Figure 4). The model utilizes the material database/expert decision support system of LeachXS ${ }^{\text {TM }}$ (ECN 2007) and the reactive transport capabilities of ORCHESTRA (Meeussen 2003). The model has been validated against laboratory measurements (Samson and Marchand 2007) of total calcium and sulfur in concrete samples exposed to external sulfate (Figures 5 and 6). The modeling framework has recently been extended to incorporate changes in elastic properties and material strength (Sarkar 2010 and Figure 7). Subsequently, Sarkar (2010) developed an uncertainty analysis framework for performing probabilistic predictions of concrete barrier durability (Figure 8).

Sarkar (2010) applied these methods to the SDF Vault 2 concrete characterized by SIMCO (2009a) for a hypothetical exposure scenario involving a sulfate concentration of $0.25 \mathrm{~mol} / \mathrm{L}=24000 \mathrm{mg} / \mathrm{L}$ (Figure 9). The exposure concentration corresponds to a Saltstone pore solution measurement reported by Langton (1987) and is held constant through time. Model simulations predict that physical damage will occur to SDF Vault 2 concrete exposed to this high level of sulfate. Three probabilistic uncertainty analysis cases were considered: 1) only physical parameter uncertainty, 2) only chemical parameter uncertainty, and 3) combined physical and 
chemical parameter uncertainty. Physical parameters are defined as model inputs other than those to the chemical equilibrium component. Chemical parameters (i.e., chemical equilibrium constants) are calibrated first and then the resulting distributions are used in the durability analysis (Sarkar 2010). Probabilistic results for this hypothetical case are shown in Figure 10 reproduced from Sarkar (2010, Figure 6.9). The median result, considering both physical and chemical uncertainty, is that the damage front will advance through the $20 \mathrm{~cm}$ thickness over a time span of about 350 years.

An examination of model inputs suggested that concrete durability is sensitive to the sulfate exposure concentration, mineral availability, and initial mineral set among other factors. Additional deterministic simulations were performed to quantify model sensitivity to these inputs as summarized in Table 3. Mineral availability refers to the fraction of total mineral content that is available for reaction and was estimated from the LeachXS ${ }^{\text {TM }}$ database. Two initial mineral sets were considered, one derived from LeachXSTM/ORCHESTRA and a second used by Samson (2010). Key observations are:

1. Durability (time for full penetration of sulfate attack front) is seen to be roughly inversely proportional to the sulfate exposure concentration as expected.

2. Incorporation of mineral availability into the analysis significantly reduces concrete barrier longevity. External sulfate attack progresses at a faster rate when fewer solid reactants are locally available to consume incoming solute reactants.

3. At lower mineral availability, the LeachXS ${ }^{\mathrm{TM}} / \mathrm{ORCHESTRA}$ and STADIUM ${ }^{\circledR}$ mineral sets produce comparable durability predictions. At higher (total) mineral availability, predictions are sensitive to the initial mineral set, especially at higher sulfate exposure. The observed sensitivity to initial mineral set is consistent with Samson (2010) who reported similar sensitivity, as mentioned in the previous section.

Concrete durability predictions should also be sensitive to the diffusion coefficient assigned to damaged portions of a thickness and the saturation state of cracks. Sensitivity to diffusion coefficient and saturation state has not been quantitatively evaluated to date.

Using the insights described above, the methods of Sarkar et al. (2010) and Sarkar (2010) could be used to generate more representative and reliable probabilistic predictions of Saltstone concrete durability through the following enhancements:

1. Create a two-layer model to more accurately simulate conditions at the Saltstone-concrete interface.

2. Define an accurate input distribution for sulfate concentration in Saltstone pore solution based on field monitoring data from ongoing SDF operations.

3. Refine and validate the initial mineral set through additional laboratory characterization of representative concrete samples.

4. Investigate whether mineral availability measurements in short-term experiments are valid for longterm durability simulations, and make corresponding modeling assumptions for mineral availability. Short-term data may underestimate the availability of certain minerals. 


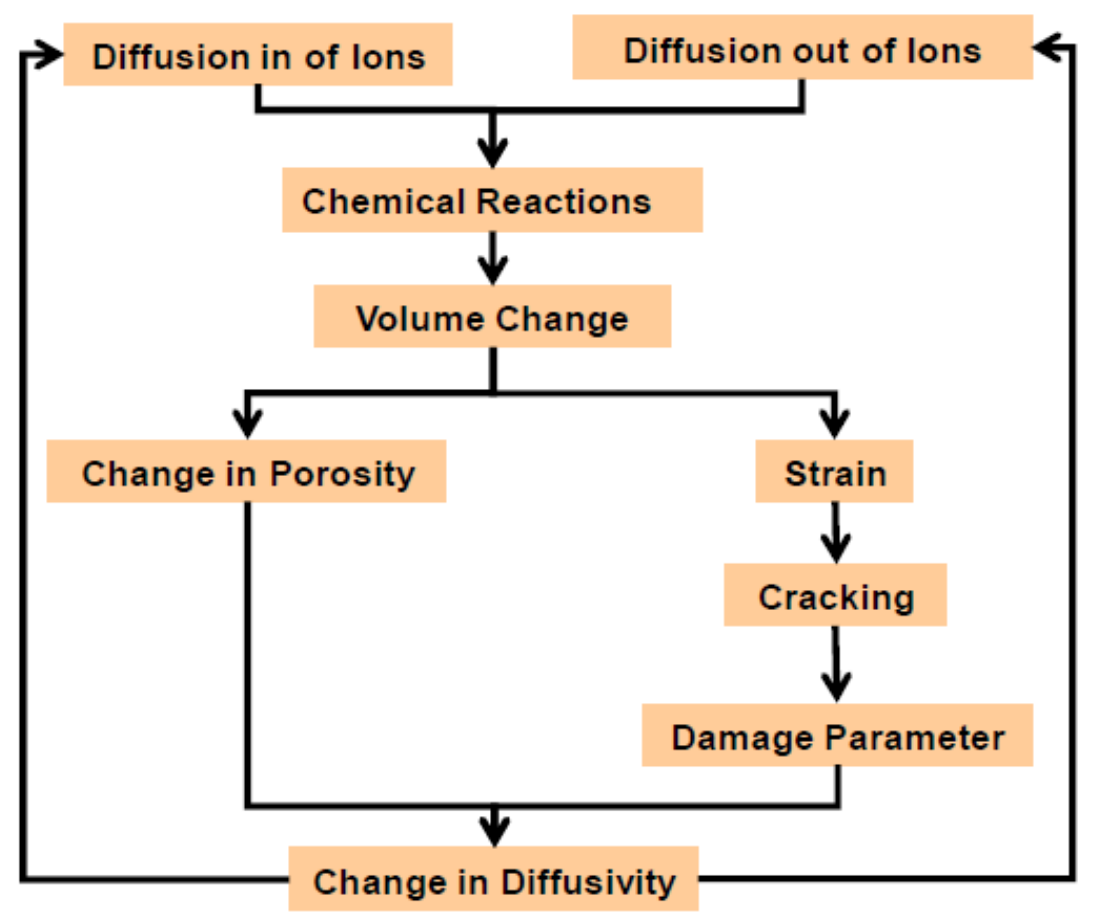

Figure 3. External sulfate attack modeling approach presented by Sarkar et al. (2010); reproduced from Sarkar (2010).

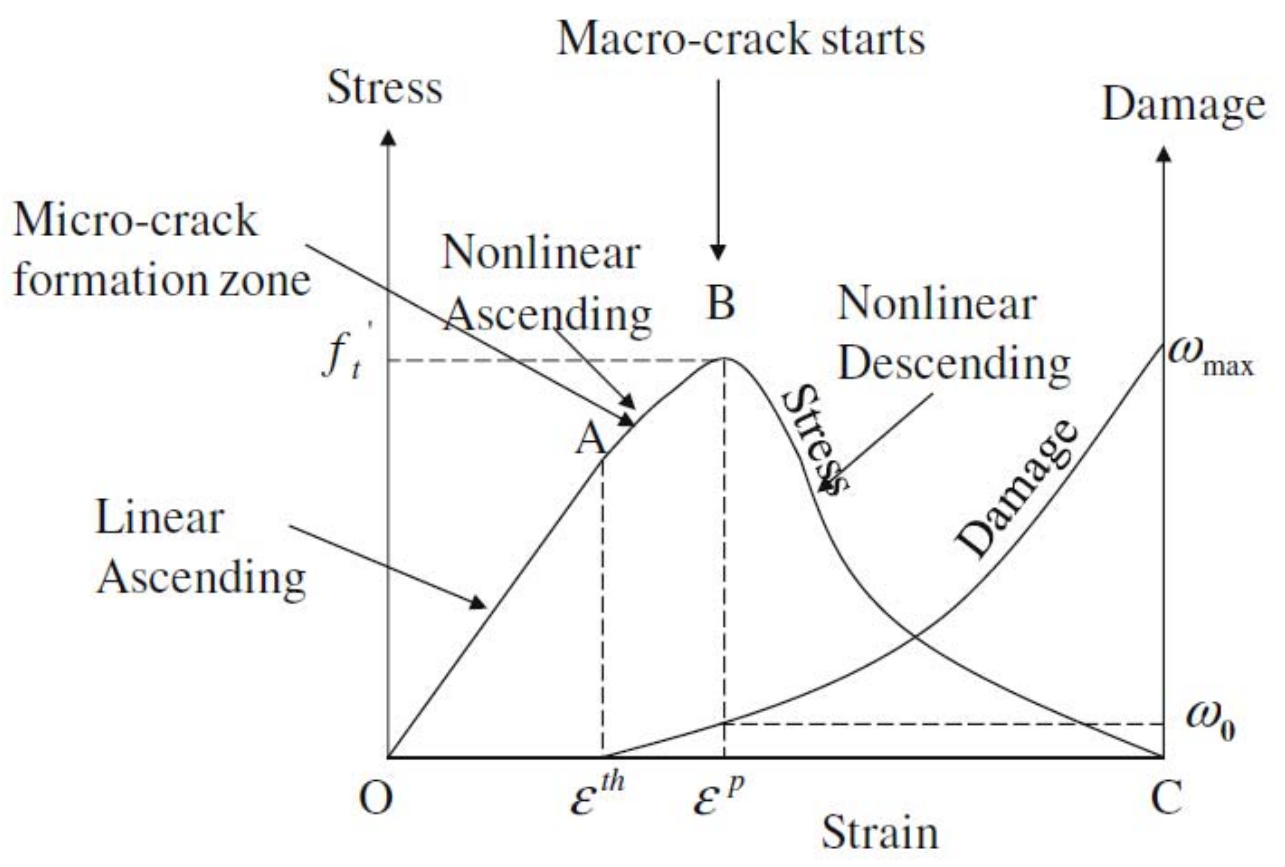

Figure 4. Stress-strain and damage relationships for concrete under tension; reproduced from Sarkar et al. (2010). 


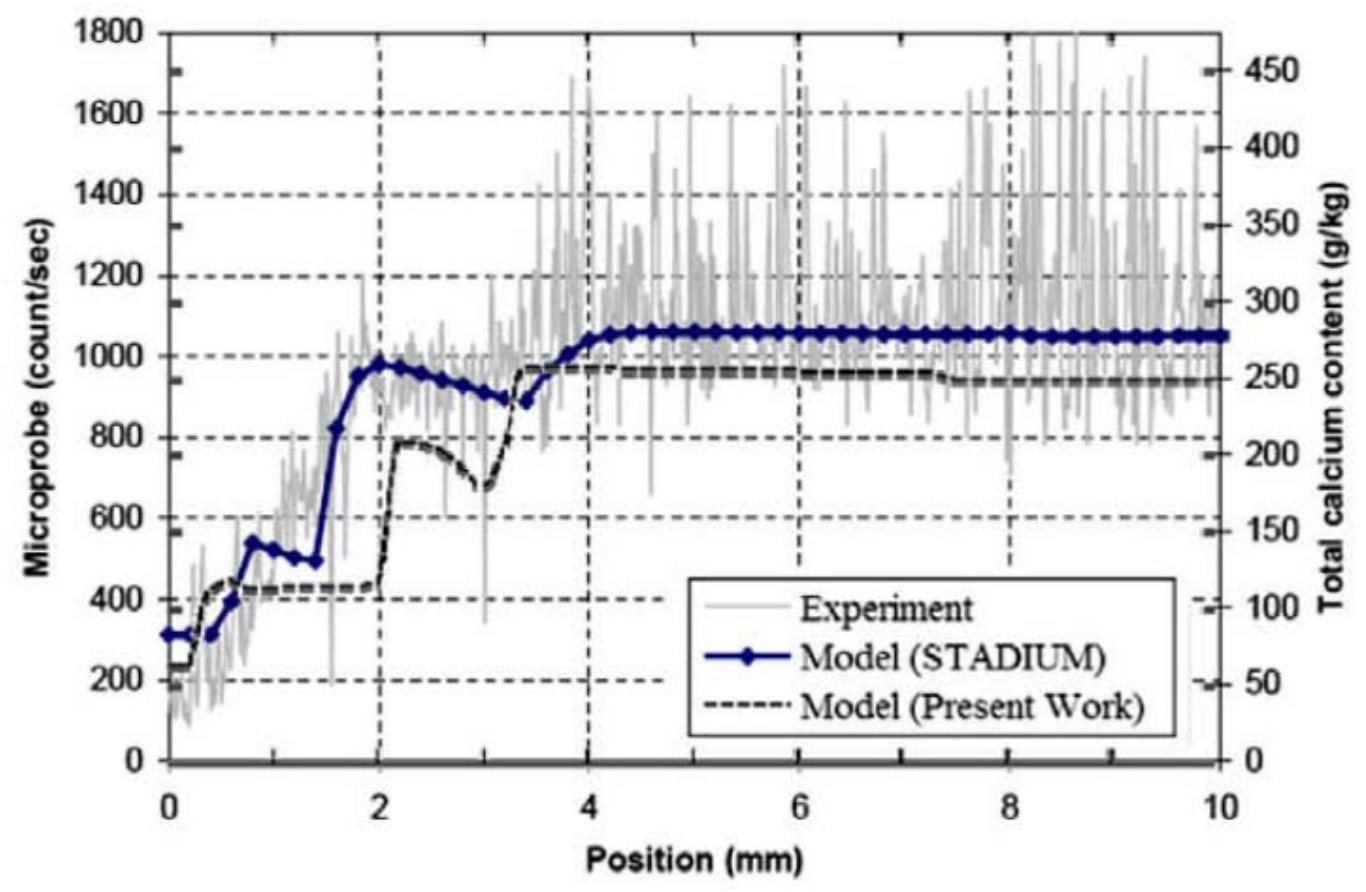

Figure 5. Measured and simulated total calcium content after one year of exposure; reproduced from Sarkar et al. (2010).

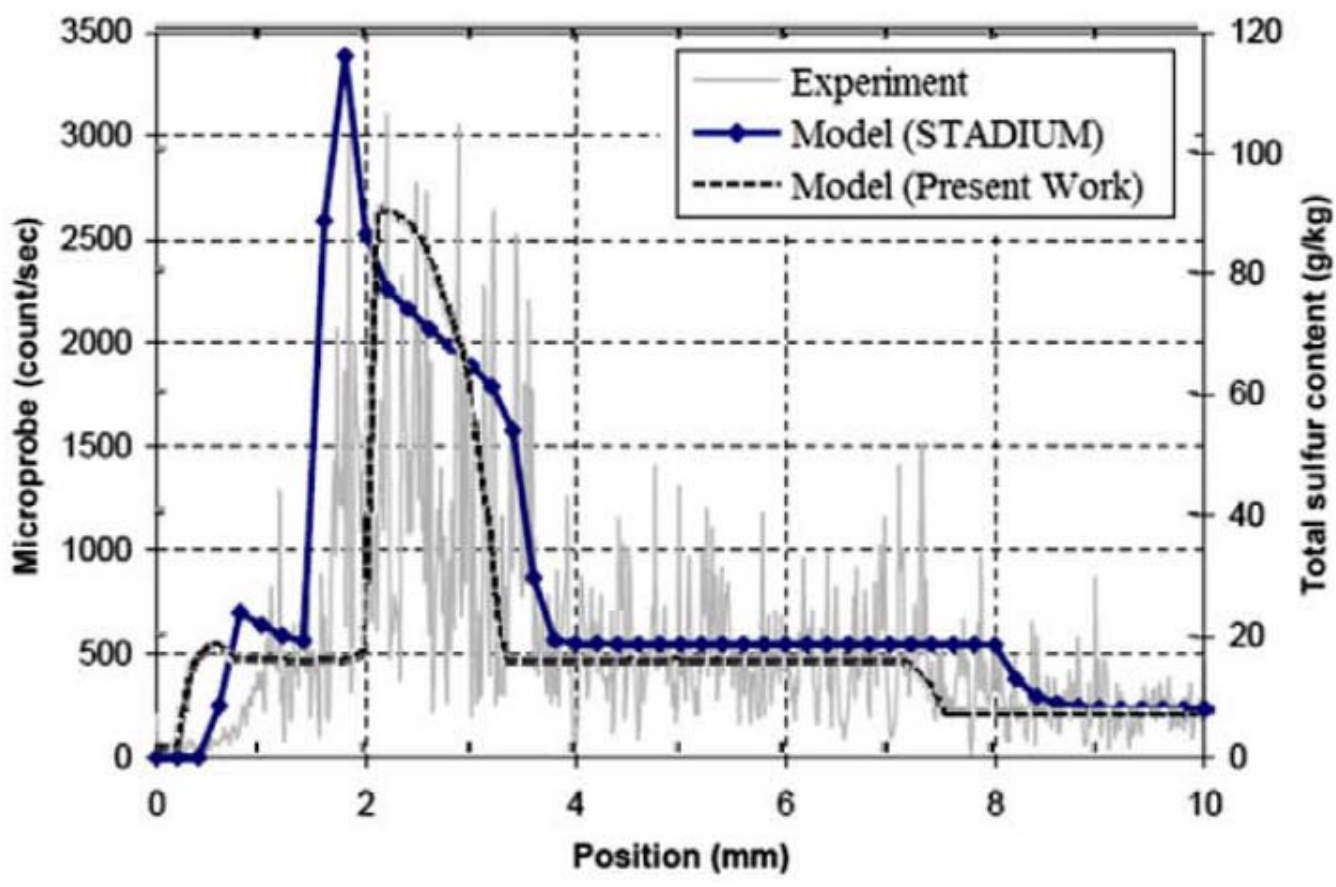

Figure 6. Measured and simulated total sulfur content after one year of exposure; reproduced from Sarkar et al. (2010). 


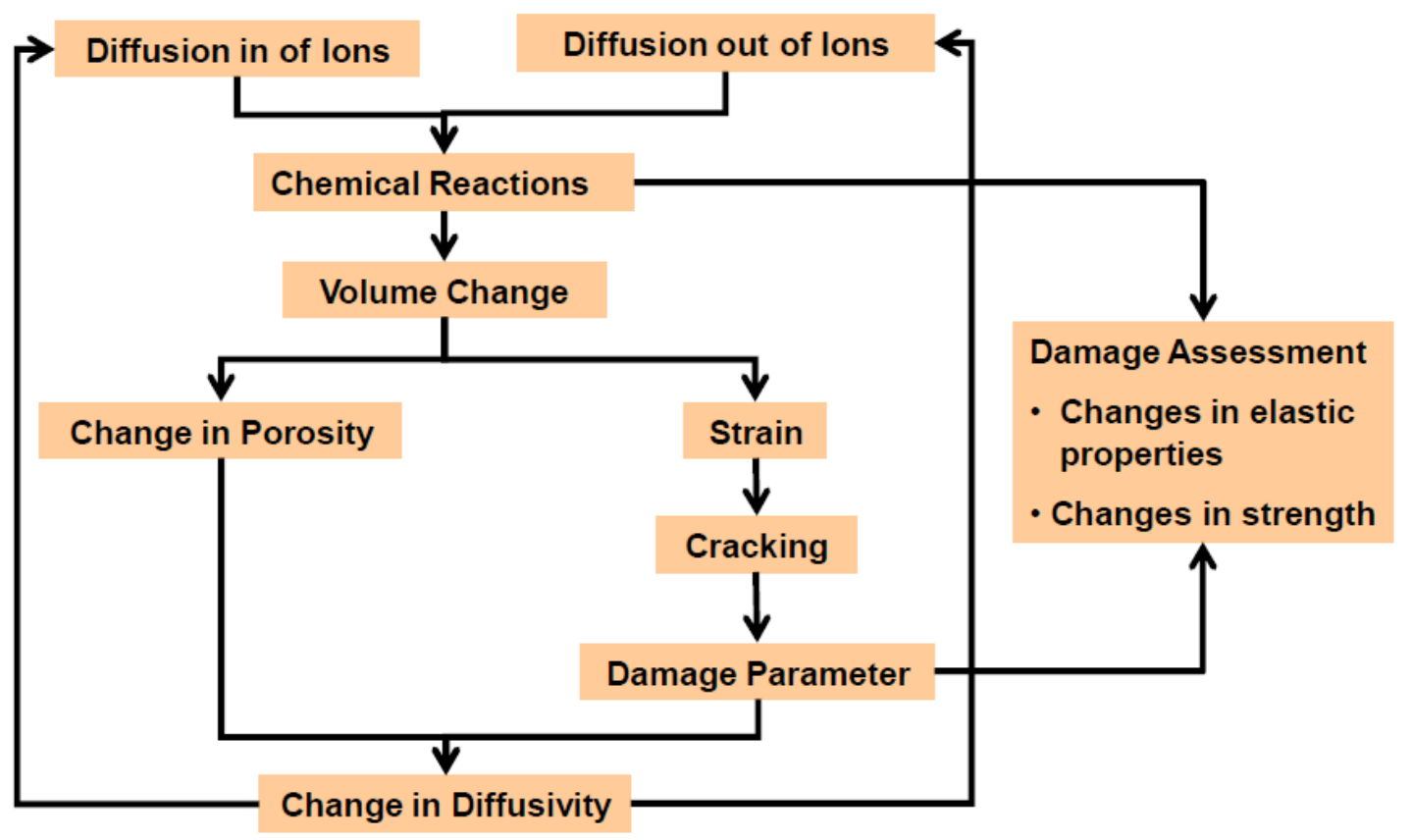

Figure 7. Extended framework for modeling external sulfate attack; reproduced from Sarkar (2010).

Repeat $\mathrm{N}$ times

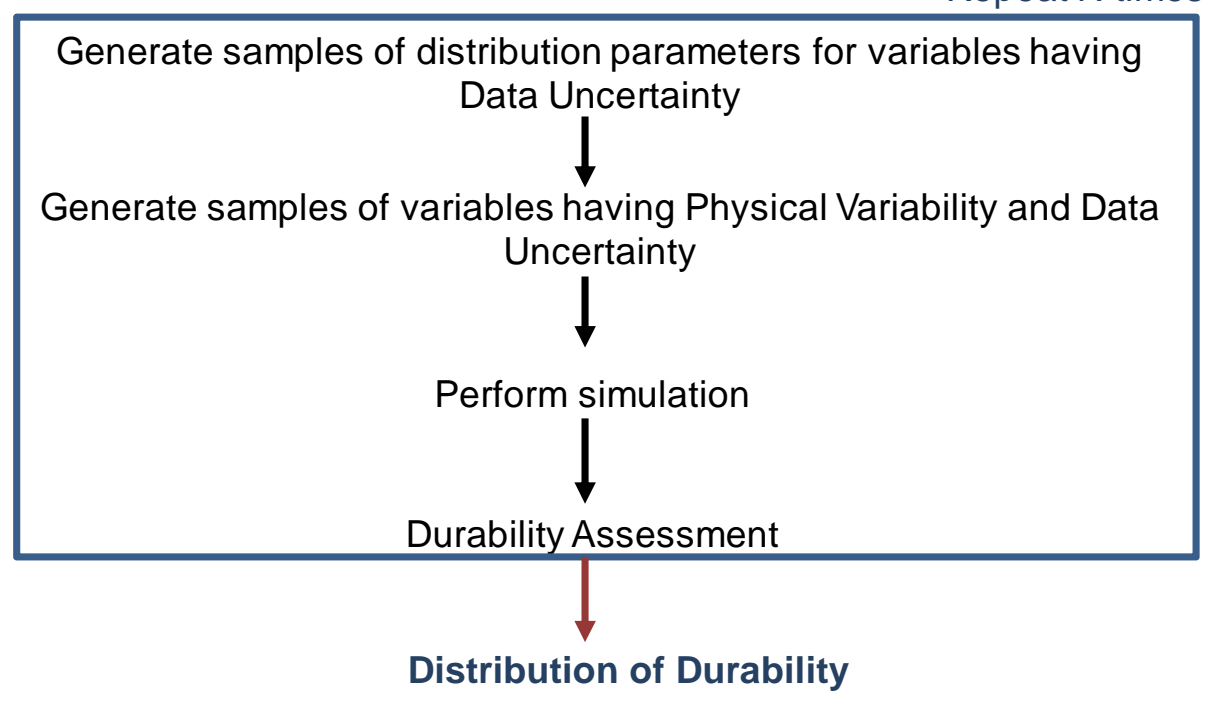

Figure 8. Probabilistic durability assessment using single loop Monte Carlo simulation; reproduced from Sarkar (2010). 


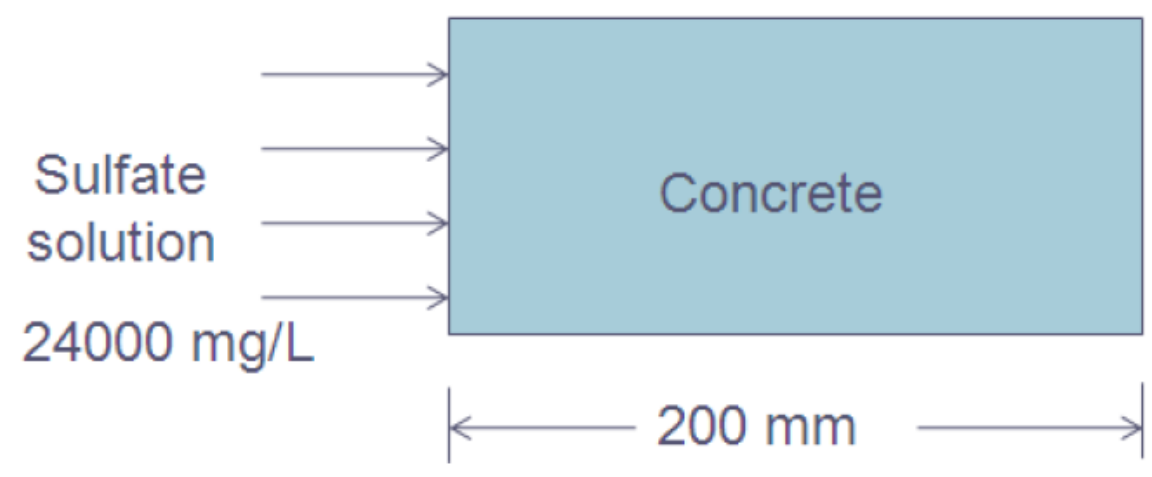

Figure 9. Sulfate exposure scenario; reproduced from Sarkar (2010).

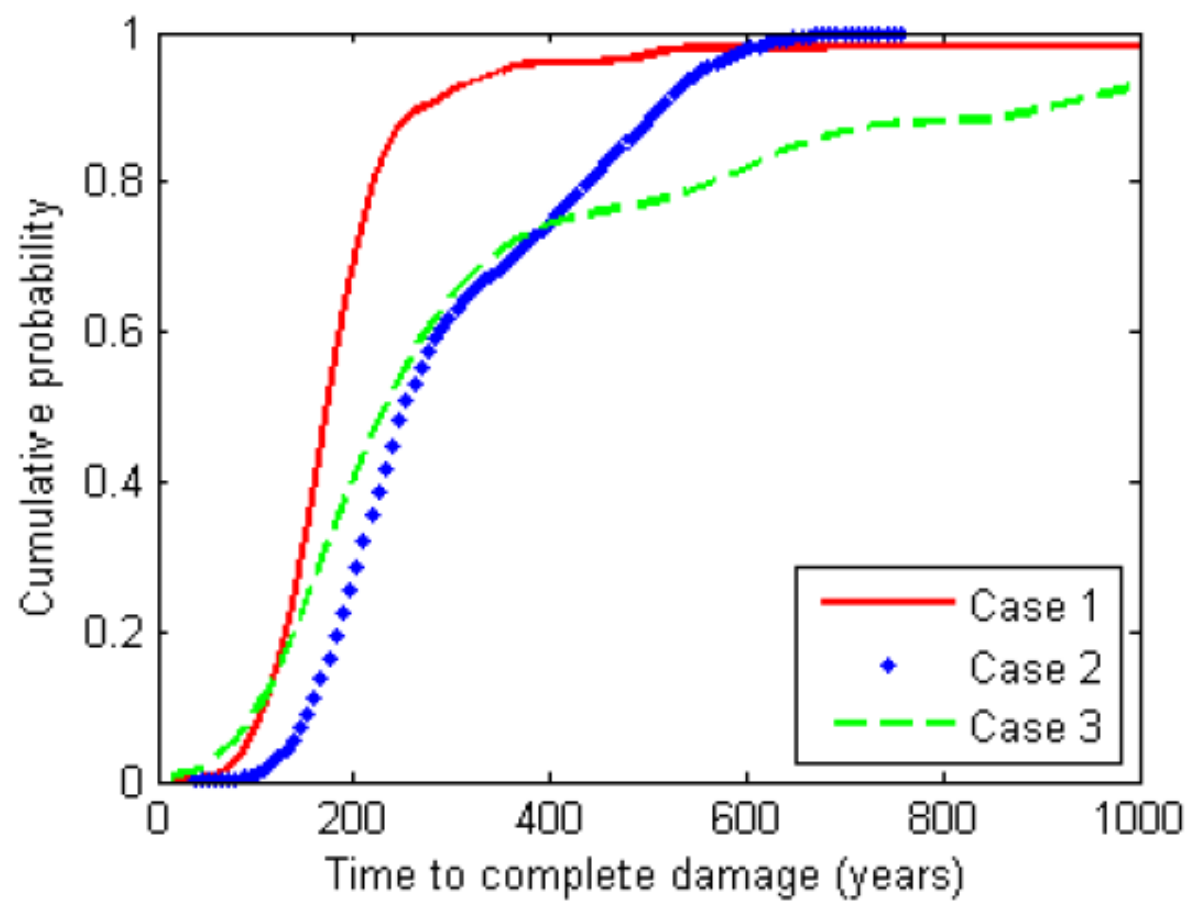

Figure 10. Cumulative probability for complete damage; reproduced from Sarkar (2010). 
Table 3. Sensitivity study of concrete durability (year).

\begin{tabular}{|c|c|c|c|}
\hline Cases & $56 \mathrm{mmol} / \mathrm{L}$ & $120 \mathrm{mmol} / \mathrm{L}$ & $250 \mathrm{mmol} / \mathrm{L}$ \\
\hline $\begin{array}{c}\text { Base case } \\
\text { (Sarkar 2010, Chapter 6) }\end{array}$ & - & - & 353 \\
\hline Available - ORCHESTRA & 1500 & 795 & 497 \\
\hline Available - STADIUM ${ }^{\circledR}$ & 1464 & 644 & 373 \\
\hline Total - ORCHESTRA & 4921 & 2664 & 862 \\
\hline Total - STADIUM ${ }^{\circledR}$ & $>10 \mathrm{k}$ & $>10 \mathrm{k}$ & $>10 \mathrm{k}$ \\
\hline
\end{tabular}

Available $=$ mineral content available for reaction from LeachXS ${ }^{\mathrm{TM}}$

Total $=\underline{\text { total mineral content }}$

ORCHESTRA = ORCHESTRA mineral set

STADIUM ${ }^{\circledR}=$ STADIUM ${ }^{\circledR}$ mineral set

\subsection{MECHANISTIC GEOCHEMICAL PREDICTIONS}

Chemical analyses supporting the Saltstone Performance Assessment are commonly based on empirical (or semi-empirical) laboratory and field-scale measurements. In the following sections, opportunities to strengthen the SDF PA with more mechanistic geochemical analyses and insights are described based on van der Sloot et al. (2010).

\subsection{Saltstone Reduction Capacity}

Saltstone is formed by mixing low-activity salt solution with a dry mix containing ground granulated blast furnace slag, Class F fly ash, and cement or lime. Blast furnace slag is included in the mix in part to create a low REDOX potential, to effectively immobilize Tc-99 waste in solidified Saltstone. Kaplan et al. (2008) reported a total reduction capacity of $822 \mathrm{meq} / \mathrm{kg}$ for cured Saltstone based on titration with Ce(IV). Kaplan et al. (2008) observed that the measured value is approximately 4 times higher than expected based on the fraction of slag present (where the other mix ingredients are not likely to have significant reducing capacity). Although potential explanations were offered, the additional reduction capacity could not be explained with confidence by Kaplan et al. (2008). 
Upon reviewing Kaplan et al. (2008), van der Sloot et al. (2010) observed that the pore solution is another source of reduction capacity in addition to the solid minerals and offered the following alternative interpretation of the laboratory test results:

"The liquid salt solution ... contains significant amounts of nitrite, which reacts as reducing agent and can be oxidized to nitrate. According to literature (Method 8351, 3) Ce(IV) will readily react with nitrite to form nitrate, so any nitrite present will contribute to the titrated reduction capacity. The fraction of the saltstone reduction capacity that can be attributed to nitrite can be estimated from the initial nitrite concentration in the salt solution. The reported concentrations range from 110 to 485 mmol per liter (Kaplan et al. 2008; Langton et al. 2009). For a concentration of $485 \mathrm{mmol}$ this results in

$$
45 \mathrm{wt}-\% \text { salt solution * } 485 \mathrm{mmol}=218 \mathrm{mmol} \text { nitrite } / \mathrm{kg} \text { saltstone. }
$$

This would be equivalent to a reduction capacity of 2 (mol of electrons per mol nitrite) $\times 218=436$ meq reducing capacity per kg solid material. This would be of similar order of magnitude as the unexplained "extra" $600 \mathrm{meq} / \mathrm{kg}$ found by Kaplan et al. (2008) who measured $800 \mathrm{meq} / \mathrm{kg}$, while 200 meq/kg was expected based on its blast furnace slag content."

Beyond the potential for the alternative hypothesis to explain the laboratory measurements, it also has important implications for facility performance. Reduction capacity present in the initial pore solution could leach from the waste form and accelerate loss of overall reduction capacity. The CBP suggests that this alternative hypothesis be investigated under the ongoing SDF PA maintenance process.

\subsection{Mechanistic $\mathrm{K}_{\mathrm{d}}$ Prediction}

Empirically determined values for sorption coefficient $\left(\mathrm{K}_{\mathrm{d}}\right)$ provide an accurate specification for the specific geochemical conditions tested, but may not be readily extensible to other conditions encountered in the future and/or under field conditions. $\mathrm{K}_{\mathrm{d}}$ estimates may also be a function of the test method employed (i.e., different testing protocols may produce different values).

To explore these issues, the CBP performed geochemical analyses aimed at assessing empirical sorption $\left(\mathrm{K}_{\mathrm{d}}\right)$ coefficients determined from laboratory experiments in relation to $\mathrm{K}_{\mathrm{d}}$ 's derived from mechanistic modeling and new testing approaches proposed by US EPA. The CBP modeling approach also makes it possible to predict changes in $\mathrm{K}_{\mathrm{d}} /$ mobility as a function of time that result from changing $\mathrm{pH}$ and REDOX conditions. The effort can provide a better understanding of the experimental observations.

\subsection{REFERENCES}

Atkinson, A. and J.A. Hearne 1990, Mechanistic model for the durability of concrete barriers exposed to sulphate-bearing groundwaters, Materials Research Society Symposium Proceeding 176, 149-156.

Basista, M. and W. Weglewski 2008, Micromechanical modeling of sulphate corrosion in concrete: influence of ettringite forming reaction, Theoret. Appl. Mech. 35, No.1-3, 29-52, Belgrade. 
Cook, J. R., E. L. Wilhite, R. A. Hiergesell and G. P. Flach 2005, Special analysis: Revision of saltstone vault 4 disposal limits (U), Westinghouse Savannah River Company technical report WSRC-TR-2005-00074 Rev. 0 .

ECN 2007, LeachXS User Manual, Energy research centre of The Netherlands, Denmark. Available from: www.leaching.org [September 1, 2009].

Glasser, F.P., J. Marchand and E. Samson 2008, Durability of concrete - Degradation phenomena involving detrimental chemical reactions, Cement and Concrete Research 38, 226-246.

Kaplan, D. I., K. Roberts, J. Coates, M. Siegfried and S. Serkiz 2008, Saltstone and Concrete Interactions with Radionuclides: Sorption $\left(K_{d}\right)$, Desorption, and Reduction Capacity Measurements, SRNL technical report SRNS-STI-2008-00045.

Langton, CA 1987, Analysis of saltstone pore solutions - PSU progress report IV, E.I. du Pont de Nemours and Company, Aiken SC.

Langton C., D. S. Kosson, A. C. Garrabrants 2009, Reference Cases for use in the Cementitious Barriers Partnership Project, Task 6 Reference Case Report.

Maltais, Y., E. Samson and J. Marchand 2004, Predicting the durability of Portland cement systems in aggressive environments-laboratory validation, Cement and Concrete Research 34, 1579-1589.

Meeussen, JCL 2003, ORCHESTRA: An Object-Oriented Framework for Implementing Chemical Equilibrium Models, Environmental Science \& Technology, vol. 37, no. 6, pp. 1175-1182.

Samson, E., 2010, Cementitious Barriers Partnership Task 7 Demonstration of STADIUM® for the Performance Assessment of Concrete Low Activity Waste Storage Structures, SIMCO Technologies, Inc., Quebec, Canada.

Samson E and J Marchand 2007, Modeling the transport of ions in unsaturated cement based materials, Comput Struct 85 (23-24),1740-56.

Sarkar, S. 2010, Probabilistic Durability Analysis of Cementitious Materials Under External Sulfate Attack, Ph.D. Dissertation, Vanderbilt University.

Sarkar, S., S. Mahadevan, J.C.L. Meeussen, H. van der Sloot, and D.S. Kosson, 2010, Numerical Simulation of Cementitious Materials Degradation under External Sulfate Attack, Cement \& Concrete Composites 32, 241252.

SIMCO Technologies Inc. 2008, Software for Transport and Degradation in Unsaturated Materials (STADIUM), Version 2.8 User Guide, September 2008, SIMCO Technologies, Inc., Available from: http://www.mslexperts.com/slm/stadium_help/index.html [February 6, 2009].

SIMCO Technologies Inc. 2008, Report; Task 1, Subcontract no. AC48992N, May 2008.

SIMCO Technologies Inc. 2009a, Report; Tasks 2 \& 4 - Experimental Results from Vault Concretes, Subcontract no. AC48992N, July 2009. 
SIMCO Technologies Inc. 2009b, Report; Task 6 - Characterization of a Saltstone mixture, Subcontract no. AC48992N, July 2009.

SRR Closure \& Waste Disposal Authority, 2009, Performance Assessment for the Saltstone Disposal Facility at the Savannah River Site, SRR-CWDA-2009-00017, Rev. 0, http://www.em.doe.gov/pdfs/SRR-CWDA2009-00017 R0.pdf.

Tixier, R. and B. Mobasher 2003, Modeling of damage in cement-based materials subjected to external sulfate attack. I: Formulation, Journal of Materials in Civil Engineering, 15, 305-313. 


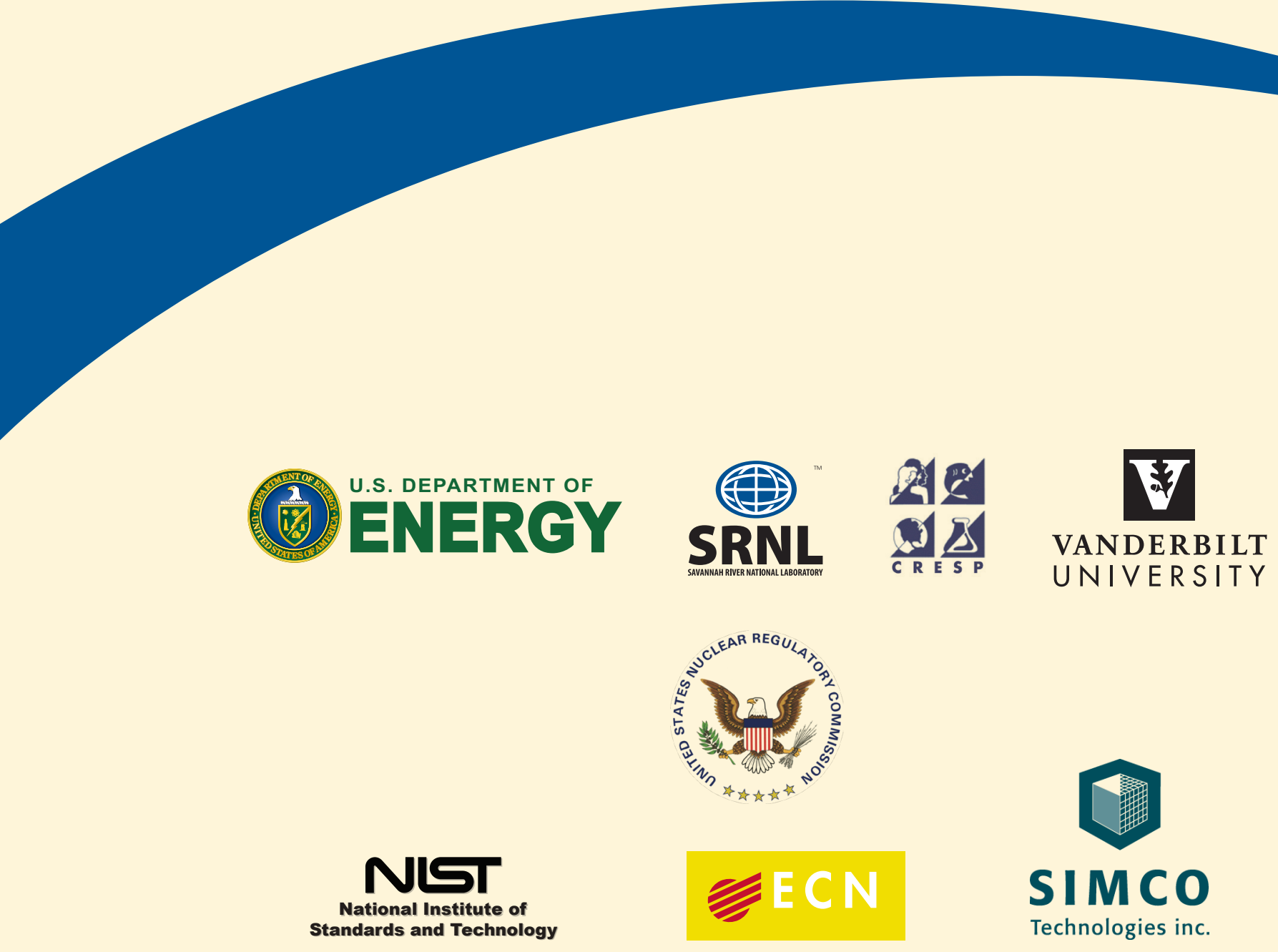

